\title{
Ortega y Gasset y la psiquiatría biológica: "Si queremos que todo siga como está, es necesario que todo cambie"
}

\author{
Ortega y Gasset and biological psychiatry:
}

"If we want that everything goes on like it is, it is necessary that everything changes"

Gustavo Figueroa C. ${ }^{1}$

\begin{abstract}
Background. Practice and research in the field of biological psychiatry requires us to assume certain positions on several philosophical issues. O bjective. To focus on the basic philosophical assumptions of modern biological psychiatry. Method. To inquire into Ortega y Gasset's interpretations of the nature of man and science in order to understand the presuppositions which biological psychiatry itself can never justify scientifically. Results. Biological psychiatry allows only the insigths of what its kind of representation has admitted in advance as a possible object, i.e., brain function, gene expression, neurotransmitter. $0 n$ the contrary and according to Ortega: "The man is not his body that is a thing, neither his soul that is also a thing, a subtle thing: the man is not at all a thing, but a drama: his life" Conclusions. Ortega can help us to apprehend the level of understanding peculiar of the current biological psychiatry better because his "new level is a deeper stratum of the philosophical problems"
\end{abstract}

Key words: Ortega and Gasset, biological psychiatry, philosophy of psychiatry. Rev Chil Neuro-Psiquiat 2006; 44(2): 134-146

$\mathrm{E}$ n el último medio siglo la psiquiatría ha experimentado un giro decisivo en diferentes planos de su quehacer teórico y práctico al pugnar por transformarse en una estricta psiquiatría biológica(1-3). El desarrollo ha sido tan espectacular que ha llegado a preguntarse, con cierta suficiencia, "¿es que existe de algún otro tipo?" puesto que "no hay algo así como una psiquiatría que sea demasiado biológica"(4). Parte importante del arrollador avance procede de las revolucionarias investigaciones en el campo de las ciencias neurocognitivas que han hecho sentir sus efec- tos por igual tanto en la clínica como en la terapéutica, en la prueba experimental como en la prevención empíricamente avalada, en la ética como en las políticas de salud menta(15-8). Como declara Kandel, las funciones mentales alteradas pueden ser explicadas ahora de manera fiel según una biología sofisticada y, tal como le ha sucedido a toda la medicina contemporánea, por fin la psiquiatría puede evolucionar desde un arte práctico a una disciplina científica basada en la biología molecular(9).

Los resultados de la nueva psiquiatría biológica

1 Departamento de Psiquiatría. Escuela de Medicina, Universidad de Valparaíso. 
trascienden las fronteras de la profesión y aún de la medicina en sentido habitual, e involucran los fundamentos de la ciencia de la vida biológica, la naturaleza orgánica del hombre y de la mente, las bases naturales de la bioética, los principios biológicos de la sociedad, en una palabra, se adentran en el área que ha sido tradicionalmente de la filosofía(10-15). Como señala Ortega, la concepción teórica surgida de la manipulación del científico, por los experimentos del biólogo, por los ensayos de los psiquiatras, es insuficiente para responder qué es, cuál es la consistencia de esa nueva realidad y, por esto, si se necesita dar razón precisamente de aquello que constituye su ser propiamente tal se debe acudir a la metafísi$\mathrm{ca}^{(16)}$. Con expresión de Heidegger, "lo que sea la biología [psiquiátrica] no se puede responder nunca biológicamente" porque, como ciencia, nunca "puede decir algo sobre ella misma con sus propios medios científicos"(17). Desde la segunda mitad del siglo XX la reflexión sobre las consecuencias de las ciencias positivas como problemas de la filosofía se revitalizó a partir de un vasto replanteamiento y profundización del originario programa neopositivista nacido de las ciencias formales así como de la epistemología y hermenéutica(18-20). Esto podría hacer suponer que nos hallamos ante aquello que tradicionalmente se ha denominado "crisis de principios" (Grundlagenkrise) de la ciencia, en nuestro caso, de la ciencia psiquiátrica, de sus fundamentos o su suelo primero que la hace posible, cuyo desarrollo llegó a un límite tal que hizo forzoso ampliar, purificándolos, esos principios ${ }^{(16,21)}$.

Por el contrario, la hipótesis del presente estudio es que la psiquiatría biológica vigente no ha modificado, en su esencia, su concepción del hombre enfermo. De esta manera, ha permanecido adscrita a los supuestos implícitos de lo que se entiende por realidad biológica y, últimamente, por realidad, y que sustenta todo el pensamiento desde la Edad Moderna, Descartes, N ewton, Galileo, la nuova scienza, a pesar de los innegables hallazgos y progresos que la han remecido violenta y decisivamente. Antes bien, quizás constituyen un impedimento para un efec- tivo vuelco substancial. Se puede plantear con las significativas palabras que el sobrino dirige al príncipe de Salina: "si queremos que todo siga como está, es necesario que todo cambie"(22).

Ortega puede ayudarnos a entender mejor el nivel de comprensión propio de la actual psiquiatría biológica porque "cada nuevo nivel es un estrato más hondo de los problemas filosóficos"(23). Si nos parece que la experiencia inherente a esta psiquiatría está a igual altura ontológica que el pensamiento biológico de toda la modernidad significa que, lo hasta aquí desarrollado, es expresión de "un insuficiente radicalismo", de no haber cavado más profundamente en sus raíces que están por debajo sustentándola y, así, ha permanecido paralizada(24). Como nos enseña apuntando a la historia de la ontología occidental, "la filosofía es una cierta idea del Ser... y toda filosofía innovadora descubre su nueva idea del Ser gracias a que antes ha descubierto una nueva idea del Pensar, es decir, un método intelectual antes desconocido"(23). Esa fue la misión de Ortega: ir más allá, sortear tanto el realismo (antiguo) como el idealismo (moderno) ocultos, por esto, trascender la metafísica del sujeto biológicamente condicionado, por medio de la "vida humana como la realidad radical: lo demás lo hay, pero no en realidad, sino en apariencia, o derivativamente" ${ }^{\prime \prime 25)}$.

La celebración del cincuentenario de la muerte de J osé Ortega y Gasset (1883-1955) es la oportunidad para recordarlo como a él le habría gustado, meditando filosóficamente sobre la realidad biológica de la persona mentalmente enferma, porque "la ciencia tiene una misión espléndida: hacer cómoda la vida de los hombres, adaptar el mundo al delirio que es el hombre. Pero la misión de la ciencia no es ser nuestra intérprete ante la auténtica realidad"(26). Lo que sucede, nos dice en otra ocasión, es que la filosofía, "siendo su tema buscar detrás del pretenso principio de ayer, otro más firme hoy, un principio que sea más principio, marcha siempre hacia atrás", se entiende, hacia "Io que nos habíamos dejado a la espalda inadvertido [y era] lo más importante" (27). Y esto es lo determinante para escoger a 
Ortega: él postulaba que su pensamiento era una inédita idea del Ser, una innovación que salta hacia el siglo XXI y, con ello, una "posibilidad de lo que ahora empezamos a hacer bajo el pabellón tradicional de la filosofía no es una nueva filosofía, sino algo nuevo y diferente a todas las filosofías"(28).

\section{El marco de referencia común de la psiquiatría biológica}

Kandel ha formulado cinco principios que, según él como neurofisiólogo -y antiguo psiquiatra-, permiten una comprensión más penetrante de las bases biológicas de la conducta tanto normal como patológica(1). Ellos son: [I] "Todos los procesos mentales, aún los procesos psicológicos más complejos, derivan de operaciones del cerebro"; [II] "Los genes y los productos de sus proteínas son determinantes importantes del patrón de interconexiones entre las neuronas en el cerebro y los detalles de su funcionamiento"; [III] "Los genes alterados no explican, por si mismos, toda la varianza de una enfermedad mental grave dada"; [IV] "Las alteraciones inducidas en la expresión génica por el aprendizaje dan lugar a cambios en los patrones de las conexiones neuronales"; y [V] "En la medida en que la psicoterapia o la consejería son efectivas y producen cambios de largo plazo en la conducta, se presupone que lo hacen a través del aprendizaje, produciendo cambios en la expresión génica que altera la fuerza de las conexiones sinápticas y cambios estructurales que modifican el patrón anatómico de interconexiones entre las células nerviosas del cerebro".

Por su parte Kendler, en su calidad de investigador y clínico practicante, ha procurado enriquecer, profundizar y suministrarle una estructura filosófica a la psiquiatría que, superando la que proyectó Jaspers en su época, esté a la altura de la ciencia más reciente ${ }^{(29)}$. Para él existen dos preguntas que están en la base de la psiquiatría: ¿Cómo se interrelacionan la mente y el cerebro? ¿Cómo integrar las múltiples perspectivas explicatorias del enfermar psiquiátrico? ${ }^{(30)}$. Kendler pretende responderlas mediante ocho propuestas que, aunque no se derivan de ninguna doctrina metafísica, dan razón de manera filosófica de la complejidad de sus preconceptos. [1] "La psiquiatría está irrevocablemente fundada en experiencias mentales, de primera persona"; [2] "El dualismo de sustancias de Descartes es falso"; [3] "El epifenomenalismo es falso"; [4] "Ambas causalidades son reales: cerebro $\rightarrow$ mente y mente $\rightarrow$ cere bro"; [5] "Los trastornos psiquiátricos son etiológicamente complejos y no podemos esperar más descubrimientos del "tipo espiroqueta" que expliquen sus orígenes en términos simples"; [6] "El pluralismo explicatorio es preferible a las teorías explicatorias monísticas, especialmente al reduccionismo biológico"; [7] "La psiquiatría necesita moverse desde una "batalla de paradigmas" precientífica hacia una perspectiva más madura que abarque la complejidad junto con modelos explicatorios pluralistas y empíricamente rigurosos"; y [8] "Finalmente, necesitamos aceptar un «reduccionismo desigual o de remiendos» con la finalidad de una integración a trocitos para tratar de explicar las complejas vías etiológicas hacia la enfermedad mental poco a poco cada vez". Sólo así, concluye Kendler, nos moveremos "desde debates estériles, impulsados por ideologías hacia problemas críticos, empíricamente conceptualizados y creativos", sin olvidar jamás las esferas mentales y psicosociales ${ }^{(30)}$.

Kandel y Kendler representan con fidelidad la postura de neurobiólogos, investigadores y clínicos de orientación biológica que, estando activos científicamente y a la vanguardia de la psiquiatría biológica presente, se han preocupado con aplicación de darle a ésta un marco conceptual sustentado en la filosofía, la filosofía de las ciencias y epistemología(31-33). Resulta claro que cada uno escoge un ámbito o zona distinta de la realidad y de la ciencia, de acuerdo a sus proyectos experimentales y en especial a su punto de partida ontológico. Las tesis de Kendler utilizan conceptos metafísicos de modo más consciente y preciso porque fueron formulados teniendo en cuenta el decisivo artículo de Kandel y, de esta forma, entregan una base más acabada. 
Este tipo de aportes no es empirismo puro, se podrían denominar laxamente pre-paradigmáticos 0 de nivel intermedio(34), que, por opción deliberada o indefinición, oscilan entre reflexionar sobre los resultados objetivos, la pragmática de la ciencia, o profundizar sobre el conocimiento científico mismo ${ }^{(35)}$. Tres objeciones surgen ante estas reflexiones. Primero, las especulaciones de ambos son similares a las heterogéneas e inarticuladas teorías nacidas de la emergente epistemología de la psiquiatría vigente que, hasta ahora, prueban que efectivamente no trascienden como todos habían esperado (36,37): no "forman un conjunto ordenado" porque "entre sí [son] independientes y no tienen precedente 0 principio" ontológico anterior(21). Como apunta H eidegger, los investigadores tienen "muchos, muchísimos pensamientos" que se pueden aplicar a la realidad a diferencia del pensador que tiene un "único" pensamiento(38). Segundo, el elaborar una metapsiquiatría, una especie de disciplina metateórica que busca integrar las aportaciones de la psiquiatría y filosofía de la mente en su utilización en la clínica así como a sus aspectos metodológicos y conceptuales, ha mostrado la insuficiencia, aún fracaso, de tal esfuerzo, por bien intencionado que haya sido concebido. En el fondo es una variedad de metaciencia, un especular que se inicia dando respuestas, apresuradas porque suponen que los hechos de la ciencia psiquiátrica tienen ya validez, antes que formularse las preguntas primeras, que son previas y se refieren a su condición de posibilidad, vale decir, qué les permite a tal es hechos constituirse en hechos para la psiquiatría ${ }^{(17,39)}$. Por último, el confuso empleo de términos como modelo, paradigma, teoría, sistema, hipótesis para dar razón de los distintos niveles en que pretende actuar, es una prueba más, e inequívoca, de un modo de pensamiento no originario(40). En otras palabras, lo que todavía no se ha planteado con precisión es la sustancia propia del tema que nos interesa responder ¿cuáles son los supuestos metafísicos que están detrás? En términos técnicos ¿cuál es su condición de posibilidad metafísica?(41), o, como diría Kant, "¿cómo es posible el conocimiento de la realidad" mental biológica, aunque esta sea enferma? ${ }^{(42)}$. En palabras de Ortega ¿cuáles son sus modos de pensar, cuáles son sus ideas del ser? ${ }^{43)}$.

\section{Lo biológico en la psiquiatría}

Ortega estaba particularmente consciente de que "en la medida en que un problema sea parcial, conserva la ciencia que lo trae un resto de actitud práctica, de utilitarismo ciego y no cognoscente, de prurito de acción y no de contemplación", en una palabra, no es una experiencia originaria del pensar sobre la realidad biológica humana ${ }^{(21)}$. De ahí que Ortega exigía retornar a la filosofía estricta, detrás de la neurociencia (Kandel), detrás de la clínica (Kendler), porque "conocer es no contentarse con las cosas según ellas se nos presentan, sino buscar tras ellas su «ser»"(16).

Bunge es un decidido y entusiasta creyente de que "vale la pena hacer buena filosofía, porque ésta brinda una posición favorable para el estudio de cualquier cosa, sea un objeto concreto o una idea abstracta", por tanto, también de la psiquiatría biológica incluidas sus particularidades y cuestiones epistemológicas(44). Siguiendo sus sugerencias antes que sus escasas referencias explícitas a la psiquiatría biológica, el sujeto mentalmente enfermo es primariamente un animal y, como tal, le pertenecen todas las características y atributos de los organismos vivos superiores, salvo que está en condiciones de funcionamiento anormal, y es humano, lo que implica una diferencia de grado antes que de esencia propiamente tal. De ahí se desprenden ciertas premisas que presumen de dar cuenta del estatuto de lo biológico al interior de la psiquiatría(45). [1] Una ontología decididamente naturalista. Naturalista, porque se ocupa de un organismo, el del hombre, y sin limitaciones, porque no acepta psique ni conducta descorporalizadas sino que, por el contrario, sostiene que lo mental y lo conductual son actividades o funciones del cuerpo (cerebro incluido); [2] Un monismo psicofísico que comprende por igual las manifestaciones mentales patológicas como propiedades emergentes de los biosistemas neuronales así como los síntomas or- 
gánicos acompañantes; [3] El hombre como biosistema está compuesto por numerosos subsistemas, cada uno de los cuales posee sus propias funciones específicas aunque permaneciendo dentro de una totalidad; enraizado en las exclusivas propiedades físicas y químicas del tejido viviente, este biosistema va más allá de estos atributos materiales y los trasciende aunque permanece condicionado por lo orgánico; [4] Una gnoseología realista. Realista, puesto que explica la realidad psiconeural, no sólo la apariencia (conducta); además, profunda porque indaga y examina el modo cómo las teorías de la psiquiatría biológica representan fidedignamente la realidad efectiva; [5] Un método plenamente científico. Al igual que el de la física, es científico porque enfrenta los problemas poniendo a prueba hipótesis y teorías abarcativas, que procuran aclarar algunos efectos macroscópicos, entre ellos el comportamiento, por mecanismos neurales y neuroendocrinos; y [6] M eta última es descubrir leyes que puedan explicar y predecir hechos del hombre psíquicamente padeciente.

\section{Biologicismo y materialismo}

Heidegger definió de manera clara el biologicismo al analizar la filosofía de Nietzsche: "Al modo de pensar que interpreta todos los fenómenos como expresión de la vida [vegetal-animal] se lo suele llamar biologicismo. La «imagen del mundo»... es biologicista"(36). Ortega lo llamó por su parte vitalismo porque, empíricamente al estudiar los fenómenos vitales, los muestra en su "arisca peculiaridad..., sin suponer tras ellos una entidad vital específica, pero, a la vez, evita su violenta reducción al sistema de la física". Por otra parte, también habló de vitalismo filosófico, "la teoría del conocimiento según la cual es éste un proceso biológico como otro cualquiera, que no tiene leyes y principios exclusivos, sino que es regido por las leyes generales orgánicas"(46). Como prototipo extremo de esta visión, en su variante de la Sozialbiologie, cita Ortega las palabras del fisiólogo Loeb: "Llegará el tiempo en que lo que hoy llamamos actos morales del hombre se expliquen sencillamente como tropismos"(47). M enos rudamente lo afirma Changeaux: "la ética normativa es sencillamente una adaptación dispuesta por la selección natural para hacer de nosotros seres sociales"(15).

¿Sería para Bunge la psiquiatría biológica re ducible a un biologicismo sofisticado? Evidentemente no. Él se apura en precisar que, aunque en principio es correcto decir que la psiquiatría biológica se entiende a partir de y adopta las técnicas de las ciencias de la vida (biología molecular, neurociencias, etc), tal enfoque es fragmentario, puesto que "puede y debe combinarse con otros enfoques, antes de ser adoptado de modo excluyente... porque tiende a pasar por al to la dimensión social de la vida humana..; puede dar cuenta muy bien de algunos aspectos humanos... pero asimismo no puede dar cuenta de rasgos humanos únicos"(44). Como resumen de su rechazo asevera con fuerza que el hombre psíquicamente enfermo posee propiedades de los que carecen los componentes biológicos puros, neurotrasmisores, neuronas, circuitos cerebrales, vías neuro-endocrinas, cerebro, y que aquellas sólo se entienden como propiedades "emergentes", no propiedades "resultantes", del nivel biológico originario puesto que aquí no se encontraban ni se podía sospechar su surgimiento(45).

Por otra parte, ¿sería la psiquiatría biológica para Bunge comprensible desde el materialismo? Se llama materialista aquella filosofía que postula esencialmente que las leyes fisico-químicas y/o sus principios gobiernan últimamente todos los sucesos de la naturaleza, incluyendo nuestros cuerpos, conductas y mentes, una especie de "divinización de la materia"(47). Esto significaría, según Slife, que una psiquiatría biológica cimentada sobre estas premisas poseería cinco supuestos filosóficos indispensables, objetivismo, naturalismo, hedonismo, atomismo y universalismo, en mayor o menor proporción o grado(48). Resumido en una frase de moda entre cognitivistas y teóricos de la informática, "el cerebro piensa", o, en otra versión, "el cerebro es una máquina, una máquina biológica, y puede pensar"(49-51), o por fin, "la conciencia es un fenómeno natural, 
biológico. Es parte de nuestra vida biológica, como la digestión, el crecimiento o la fotosíntesis"(49).

N uevamente, Bunge se opondría con vigor. El materialismo triunfante del cual él es representante concibe a la psiquiatría biológica desde un materialismo emergente, muy diferente del tradicional del siglo XX, tal como ya había sido también criticado con acidez por Searle Ilamándolo inverosímil ${ }^{(13)}$. Acepta Bunge que toda entidad, por ejemplo una depresión mayor, es causada y explicada como una interacción entre elementos del cerebro a micronivel. Pero como emergentista él afirma que los afectos de desesperanza y pensamientos depresivos de ruina no pueden ser deducidos o calculados a partir de la mera estructura biológica neuronal, por ello, es una propiedad "emergente", tiene atributos que no aparecen en los niveles inferiores que la constituyen y posee una jerarquía sistémica que va evolucionando onto y filogenéticamente $y$, de este modo, va más allá de la materia física ${ }^{(52)}$. Para Bunge la psiquiatría biológica, como otros tantos proyectos de investigación empírica, está, por fin, sustentada en una firme "ontología de bases científicas": exacta, sistemática, científica, materialista, dinamista, sistemista, emergentista, evolucionista. Empero, de pasada, admite que la filosofía en general se encuentra hoy en una grave crisis. "Pero la buena noticia, nos dice, es que la filosofía ha atravesado crisis anteriores y, cada vez, las ha superado"(44).

\section{El imperialismo de la ciencia}

"Hacia 1750 comienza el reinado de la física", esto es, de la ciencia, porque esta es la ciencia por excelencia, piensa Ortega(23). Esto es, define autocráticamente lo que es la realidad, por cuanto la determina últimamente como física o natural 0 material, dictamina su área o extensión y cuáles son los conocimientos que son auténticos saberes. Así se entiende el tono casi triunfalista de Kandel, Kendler y en especial de Bunge, además de la íntima convicción de la trascendencia de sus enunciados sobre las bases epistemológicas de la psi- quiatría biológica, enunciados que presagian su futuro inmediato como un desarrollo acelerado producto de una profundización de ellos "iQué tremendo descubrimiento!", nos persuade Kandel, "Aquí tenemos, por vez primera, las bases neurales para un conjunto de procesos mentales inconscientes" ${ }^{\prime 1)}$. El éxito conseguido, inesperado tanto como espectacular, significa haber empezado ya a recorrer con paso firme el "seguro camino de la ciencia", der sichere Gang, como gustaba decir a Kant. Aunque, nos previene Ortega, esto puede querer decir pretensión de "dominar todas las demás", sin contrapeso efectivo, en una suerte de terrorismo de los laboratorios ${ }^{(53)}$.

¿Hemos conseguido alcanzar por fin, después de este detenido recorrido por la neurociencia, la clínica y la filosofía de las ciencias, los fundamentos primeros de la psiquiatría biológica? Luc Ferry piensa que no y, mas aún, acusa a que los fundamentos materiales, postulados por el biologicismo como originarios, se disimulan detrás de ciertas seducciones que ejerce este materialis$\mathrm{mo}^{(54)}$. Por una parte, en "el orden de la sospecha, de la desmitificación", el materialismo pre tende por esencia "saber más" ya que se libera de las ingenuidades de las teorías al uso y, desde esos momentos, aparecen estas como encubriendo las "verdaderas razones", más allá de la apariencia de los síntomas de la manía se oculta una modificación de la serotonina y noradrenalina, o sea, se puede descodificar hasta conseguir lo más genuino y real. Por otro lado, en el orden de las ideas, seduce al no aceptarlas en su sentido literal sino asegura "partir de los hechos" mismos, interesarse, por así decirlo, por "las auténticas realidades", los neurocientistas no hablan en los maníacos de sus impulsos de muerte dirigidos hacia la figura interna de los padres, una abstracción interesante pero no verificable ni palpable, sino de lo que "efectivamente sucede", y que se muestra tangiblemente alterado al examen imaginológico, el cerebro límbico.

Pero Ferry va más allá al imputar a que el materialismo o naturalismo, sustrato de la psiquiatría biológica, significa tanto un reduccionismo como un determinismo. Reduccionismo, 
porque termina naturalizando no sólo los actos y comportamientos, sino finalmente el pensamiento, la ética y la cultura, aunque a veces la ciencia lo oculte bajo el ropaje que sus resultados son todavía parciales o meras hipótesis de trabajo. La ciencia es modesta de hecho, pero no de derecho: de jure asevera que todo es explicable a la larga de manera orgánica y es cosa de tiempo y aplicación rigurosa de igual metodología, de ahí que Husserl se quejaba de que el psicologismo, variedad del naturalismo, al identificar a la conciencia con procesos orgánicos, transmuta de modo ilícito los "hechos" psicológicos singulares en "principios" puros o "leyes" normativas universales; así, los axiomas matemáticos se explican a partir de los mecanismos de abstracción que ejecuta maquinalmente el cerebro ${ }^{(55)}$. Determinismo, porque aún al insistir en la importancia del "medio" (infancia, familia, cultura) como condicionante de los comportamientos alterados, corrientemente pasa insensible y subrepticiamente del determinismo de lo orgánico al determinismo del entorno social, afectivo, biográfico, etc, es que este entorno es concebido al final de un modo determinista, él mismo determinado y determinante ${ }^{(54)}$.

Si se aplican los conceptos de Popper caeríamos en la no falsabilidad del materialismo ¿Cómo podríamos estar seguro de que este 0 aquel síntoma de la esquizofrenia no es material, no está determinado por su neuro-química o sus genes? Precisamente, la ausencia de modificaciones del lóbulo occipital es una demostración por cuanto escapa, pero sólo por estos momentos o circunstancias: por ser no sabida por ahora o no contarse aún con la técnica adecuada para precisar su sustrato somático(56). Como teoría total tiende a integrar en ella misma todo hecho que pudiese contradecirla, lo incorpora con la figura de supuesto hallazgo ubicado en un futuro indeterminado.

\section{El realismo de la psiquiatría biológica}

Volvamos a la pregunta sobre los principios últimos de la psiquiatría biológica. Ortega ase- vera: "formal o informalmente, el conocimiento es siempre contemplación de algo a través de un principio. En la ciencia esto se formaliza y se convierte en método o procedimiento deliberado: los datos del problema son referidos a un principio que los «explica». En filosofía esto se lleva al extremo, y no sólo se procura «explicar» las cosas desde sus principios, sino que se exige de estos principios que sean últimos, esto es, en sentido radical «principios»"(23). Por ello con Ortega partiremos desde un punto absolutamente diferente: los hechos de la psiquiatría biológica. ¿Son los datos de la psiquiatría biológica radicales? El acento está puesto en lo "radical": no es lo más importante, ni lo más necesario, ni lo más científico, ni lo más racional. Radical significa que está en la raíz misma del saber. Vale decir, si la pregunta se dirige a averiguar si los hechos que entrega la psiquiatría son radicales, lo que indaga es si son evidentes e incuestionables, si son realidades irrefutables, si están más allá de cualquiera duda, especialmente si esta es sistemática, metódica y extremada. ¿Existe el trastorno obsesivo de manera incontrovertible, es el trastorno de pánico un hecho irrebatible, es del todo innegable la catatonía aguda letal? Parece claro que no lo son de modo primario. Lo que no significa negar la posible verdad de estos cuadros clínicos puesto que quizás tienen una vigencia derivada 0 inferida o colegida, lo que admite "acotar su vigencia al orden secundario de fenómenos a que se refieren, orden de fenómenos que no pretende ser radical"(24). Pero entonces cabe una pregunta ulterior y más decisiva. Si todos estos hechos de la psiquiatría biológica son dudosos y secundarios ¿no poseerán firmeza si se apoyan en una realidad tras ellos que sea ella misma categórica? Esta es una respuesta que le incumbe a la filosofía misma porque "el problema primero de la filosofía no es averiguar qué realidad es la más importante, sino qué realidad del Universo es la más indudable, la más segura, aunque sea, por caso, la menos importante, la más humi lde e insignificante" (24).

Lo que sucede es que la ciencia moderna, léase la psiquiatría biológica, no busca la realidad 
radical de los fenómenos porque la llamada realidad científica es una realidad dependiente y no absoluta, una cuasi realidad, porque es condicional y relativa al hombre. Es el científico el que, a través del experimento, manipula, interviene, obliga, coacciona a la naturaleza obligándola a responder ${ }^{(17)}$. "N o es, pues, la N aturaleza, sin más y según ella, lo que el experimento nos revela, sino sólo su reacción determinada frente a nuestra determinada intervención"(16). Y además, lo que al científico le interesa no es la esencia o consistencia última de los fenómenos, "el conocimiento del mundo sensu stricto," sino tan sólo su exactitud y la certidumbre de sus hallazgos, certidumbre adquirida por cualquiera de los dos criterios establecidos de certidumbre: "la deducción racional o la confirmación por los sentidos"(16).

Esto lo vio agudamente Zubiri cuando afirmó que lo que se propone conseguir el investigador -el psiquiatra, el neurocientífico- es la exactitud de su conocimiento por sobre toda otra consideración, "la inexorable necesidad objetiva"(57). "El rigor científico", continúa Zubiri, "no significa tanto la posesión de la interna necesidad de las cosas, sino la precisión objetiva.., [por lo cual se] sustituye las cosas llamadas empíricas, las cosas tales como aparecen en la vida corriente, por otras cosas que se comportan relativamente a las primeras, como el límite a las fluctuaciones que a él se aproximan...;[en lugar de] penetrar en las cosas para explicarlas, la ciencia trata, en buena parte, de sustituirlas por otras más precisas"(57). En pocas palabras, la psiquiatría biológica "trata de averiguar dónde, cuándo y cómo se presentan los fenómenos" mentalmente patológicos, dejando de lado qué son o cómo tiene que ser las enfermedades mentales "que así se manifiestan en el mundo".

Al proceder de esta manera el psiquiatra biológico obedece con aplicación a los estrictos cánones del científico actual que se desarrollaron de manera reglada a partir de la modernidad. Cuando estudia un fenómeno psíquico o conductual da por entendido que este posee una " «naturaleza», un modo de ser definitivo, permanente, inmutable" por detrás de los cambios, más allá de sus modificaciones, sosteniendo sus mutaciones, sustentando sus transformaciones, respaldando sus evoluciones(58). Parecería que esta afirmación contradice lo que persigue el investigador y aún el sentido común: atenerse a los "fenómenos manifiestos" que, de suyo, siempre van mudando, innovándose, evolucionando. Aún así es una contradicción aparente. Desde Galileo y N ewton el apoyo empírico para los ensayos ha tenido una suposición básica previa: "la homogeneidad del universo, en distribución y movimiento"(59). Gracias a esta homogeneidad presupuesta de los datos positivos ha sido posible la búsqueda de regularidades o leyes, regularidades que son "consecuencias inexorables de su propia constitución o naturaleza"(59). A esta homogeneidad del universo Aristóteles la llamó naturaleza, natura, physis.

"Pero esto es lo que para Aristóteles era la «sustancia» de lo que se mueve, de lo que cambia. Physis, natura, es la forma especial que la sustancia adopta en lo cambiante"(59). El ser griego es, pues, "el ser substante o sustancial, ser inmóvil e invariable", no sólo "el soporte de las cualidades, es el sujeto permanente de sus variaciones o accidentes"(24). Conviene profundizar y recordar que para A ristóteles la sustancia o ousía tiene tres atributos que son decisivos e interconectados entre sí: es independiente del hombre y aún "independiente de todo otro algo", está separado de todo o es «por sí» y, por último, es suficiente o se basta a sí mismo o posee autarquía, es "suelto de los demás, ab-soluto"(26).

Con estas nuevas aclaraciones se tiene la impresión que la psiquiatría biológica tiene como principio ontológico un materialismo distinto que el propuesto por Kandel, Kendler y Bunge, materialismo que se asienta en un naturalismo (physis) y este finalmente en el ser sustancial o sustancia (ousía) con sus atributos de independencia, suficiencia y autarquía. Pero Ortega, va más allá y hace hincapié con sutileza que Aristóteles, al hablar de "sustancia", todavía no entra al campo propio de la filosofía primera, lo que se iba a llamar después "ontología". "La ontología sensu stricto nos dice qué algos son genui- 
nos entes y cómo lo son"(26). Lo que busca el Estagirita es el verdadero ente, que es una cuestión previa y más básica todavía porque se mueve en la esfera del "ser" y, por eso, él se esfuerza por revisar concienzudamente todos los algos que son sustancias. Al finalizar el libro $Z$ de la M etafísica dictamina que son este hombre, este cabaIlo, esta planta, esta mesa, etc. En el cotidiano hablar les Ilamamos de modo laxo cosas: "entendemos por «cosas» los algos que son por su propia cuenta, fuera de nuestras ideas, sueltos, independientes entre sí y del hombre"(26). Aquí se detiene Aristóteles y puesto que "cosa" se dice en latín res, su posición ha sido llamada con justeza "realismo". Heidegger llama a ésta la ontología de la presencia (Anwesen) ${ }^{(60)}$. 0 como explica en otra parte: "«Ser» quiere decir desde la temprana Grecia hasta los últimos tiempos de nuestro siglo: estar presente [presencia]"(61).

Al dar este paso Aristóteles dejó condicionado a todo el pensamiento occidental hasta nuestros días, por más que distintos pensadores hayan intentado saltar de su ámbito de influencia, o en expresión de Ortega, se haya aspirado a bajar de nivel ontológico, puesto que "cada nuevo nivel es un estrato más hondo de los problemas filosóficos desde el cual se ven los antecedentes por debajo de ellos, en el secreto de sus raíces"(23). Así, H eidegger habla de tres experiencias distintas de la ciencia en Occidente: la griega (episteme), la medieval (doctrina, scientia), la moderna (investigación) ${ }^{(62)}$. Empero todas se pueden condensar en una frase: "el pensar [la ciencia] como un resultado del ser [cosa, res]" (24). Lo que presupondría, pero esto no lo trató Aristóteles sino lo dejó a sus espaldas, que la estructura o textura del ser coincide por completo con la del pensar, ¿y si no, sería incognoscible en absoluto?

En otros términos, la psiquiatría biológica actual está referida y sustentada en su teorizar y actuar por "la sustancia" (ousía) que va más allá de la ciencia de la Edad M oderna y se interna en la Grecia clásica con la "cosa" (res), en cuanto ente primero o ente propiamente tal. Esto es, el principio metafísico conductor de la psiquiatría biológica es el realismo, o "cosismo".

\section{Conclusión: La vida humana como realidad radical de la psiquiatría biológica}

La triunfante psiquiatría biológica actual ha procedido en su quehacer sin preguntarse con detención ni hondura sobre los principios o supuestos metafísicos que la están permitiendo y a la vez determinando, quizás limitándola porque permanecen desconocidos bajo sus pies ${ }^{(63)}$. Si acudimos a Ortega fue porque él ha diagnosticado con particular sutileza los fundamentos de la ciencia actual: el realismo metafísico con todas sus implicancias. Empero Ortega progresa incluso más porque él se declara como estando en un puesto de avanzada ya que busca trascender el "realismo" (incluido el "idealismo" estrenado por Descartes porque este mantuvo restos de "realismo"), hacia un nuevo modo de pensar y, con ello, de iluminar la realidad(64).

H eidegger apuntó hacia nuestras insuficiencias ontológicas como psiquiatras biológicos cuando aseveramos con ingenuidad que nos relacionamos con "hombres" y sus "mentes", insuficiencias que no pueden ser desconocidas ni minimizadas. "Al Ilamar «hombre» al existente que se va a interrogar", nos previene H eidegger, "se le pone ya de antemano dentro de una determinada concepción categorial", y con tal "definición por pauta viene prescrita la descripción de una perspectiva determinada, sin que con ella se recuperen activamente, haciéndolos propios, los motivos originarios de tal perspectiva"(65). ¿Qué significa esto? La psiquiatría biológica se preocupa del enfermo en su funcionamiento psíquico y físico porque los entiende finalmente como animales superiores aquejados en la razón. "En principio se piensa siempreen el homo animalis", dice Heidegger, "aún cuando se entienda el anima como animus sive mens, y después como sujeto, persona, espíritu. Este poner uno por otro es propio de la Metafísica. Pero, por esto, no es considerada a su altura la esencia del hombre, ni pensada en su procedencia... La M etafísica [occidental] piensa al hombre desde la animalitas y no lo piensa hacia su humanitas"(66). Animal rationale es la tra- 
ducción latina del zóon lógon ékhôn griego que conjetura una substantia o ousía que proviene del helenismo de Aristóteles y que ya ha dado un paso decisivo pero irreversible hacia la entificación (reificación) o la presencia (Anwesen) sin interrogarse por su esencia que le es más propia. Con otras palabras, todo estudio del "hombre", antropología, la psiquiatría como antropología del enfermo mental, es limitado y corto porque no se ha inquirido con antelación de donde procede esta denominación de "hombre", cuáles presupuestos están por debajo: "la antropología es aquella interpretación del hombre que, en el fondo, ya sabe qué es el hombre y por eso no puede preguntarse nunca quién es. En efecto, si hiciera esa pregunta, tendría que declararse traspasada"(66). Heaquí el motivo por el cual no es intrascendente usar términos como hombre, persona, conciencia, yo, sujeto, psiquis, espíritu, mind, embodied mind (u otras similares que pertenecen a distintos períodos de la historia de la ontología occidental) en la psiquiatría biológica(67).

Ortega no comparte muchos de los asertos de Heidegger aunque los anteriores los acepta ya que están en parecido nivel de radicalismo. En otros términos, los dos ya han ido más allá del "realismo" e "idealismo", las dos grandes metáforas del pensar occidental(68). En el caso de Ortega hacia la "vida humana" como realidad radical, muy diferente a Heidegger que habla del Dasein o Ek-sistenz ${ }^{(69)}$. Con la conocida expresión de H egel que gustaba a Ortega, su altura ontológica le parece a él que es una auténtica Aufhebung, una absorción que supone una conservación y una superación al mismo instante. Ambos estadios anteriores (realismo, idealismo) encuentran su verdad en el siguiente de Ortega (vida humana), que puede ser el nuestro si nos esforzamos como psiquiatras biológicos. Ahora se puede entender bien la famosa frase de Ortega que es una respuesta a nuestra interrogación inicial: "La vida humana es una realidad extraña, de la cual lo primero que conviene decir es que es la realidad radical, en el sentido de que a ella tenemos que referir todas las demás, ya que las demás realidades, efectivas o presunta, tienen de uno u otro modo que aparecer en ella", la psiquiatría biológica es una realidad que aparece al interior de la vida humana y desde allí pueden entenderse sus hallazgos, sus hipótesis y sus respuestas(70).

Ortega esbozó algunas de las características de esa nueva manera de entender al hombre, incluido el enfermo psíquico, analizando someramente algunas particularidades de la biografía del gran Goethe (Goya, Vives, Velásquez), que tienen una importancia decisiva, aún programática para la futura psiquiatría biológica(71). "Ese yo que es usted, amigo mío, no consiste en su cuerpo, pero tampoco en su alma, conciencia o carácter"(72), así como tampoco en ninguno de sus atributos 0 dotes que se conocen como la inteligencia, la memoria o la voluntad. "Usted se ha encontrado con su cuerpo, con un alma, con un carácter determinados, lo mismo que se ha encontrado usted con su fortuna". El psicopatólogo, aún el más perspicaz y advertido, que intenta de buena fe penetrar en él, en el dentro del hombre, sólo consigue "descubrir todo el aparato de relojería que forma el carácter y, en general, el alma del sujeto",... pero ¡cuidado! "la biografía necesita de la psicología [y psicopatología] como de la fisiología. Pero todo ello es pura información"(72). Con términos aún más elocuentes: "No es el hombre propiamente su cuerpo ni es propiamente su alma. Ambos son mecanismos, físico el uno, psíquico el otro, con que se ha encontrado y mediante los cuales, como instrumentos u órganos más próximos, tiene que esforzarse en existir"(73). O lo que es lo mismo, "el yo que usted es se ha encontrado con estas cosas, corporales o psíquicas al encontrarse viviendo. U sted es el que tiene que vivir con ellas, mediante ellas, y tal vez se pasa usted la vida protestando del alma con que ha sido usted dotado... El alma queda, pues, tan fuera del yo que es usted como el paisaje alrededor de su cuerpo"(72).

Quizás por lo anterior se quejaría Ortega de la confusión de principio que está en la base misma de la psiquiatría "biológica" al malentender bíos por zoé y que no le permitiría entrar de lleno en el naciente siglo XXI. Bíos es la vida biográfica, la biografía entendida como "haz de pro- 
yectos para ser, de aspiraciones, en un programa de vida..., pugna por realizarse en un elemento extraño a él, en lo que llamo la circunstancia"(74). Totalmente diferente a la "zoé, a la vida en sentido biológico, zoológico. La zoé consiste en el funcionamiento mecánico y mecánico desarrollo de los mecanismos con que el animal a nativitate se encuentra dotado"(74). En expresión exacta, la "psiquiatría biológica" actual en rigor es una "psi- quiatría zoológica". Por lo que si la psiquiatría biológica quiere ser no solamente "biológica" sino "psiquiátrica", si "[no] queremos que todo siga como está, es necesario que todo cambie [en realidad]", debe recordar la admonición de Ortega: "El hombre no es su cuerpo, que es una cosa, ni su alma, que es también una cosa, una sutil cosa: el hombre no es en absoluto una cosa, sino un drama: su vida"(74).

\section{Resumen}

Antecedentes: La práctica e investigación en el campo de la psiquiatría biológica exige que asumamos posiciones en varias cuestiones filosóficas 0 bjetivo: Centralizarse en los supuestos filosóficos básicos de la psiquiatría biológica moderna M étodo: Investigar las interpretaciones de Ortega sobre la naturaleza del hombre y la ciencia para comprender los presupuestos que la psiquiatría biológica no puede justificar científicamente Resultados: La psiquiatría biológica permite visualizar sólo aquello que su tipo de representación ha aceptado antes como objeto posible, ej., función cerebral, expresión génica, neurotrasmisores. Por el contrario y de acuerdo a Ortega: "El hombre no es su cuerpo, que es una cosa, ni su alma, que es también una cosa, una sutil cosa: el hombre no es en absoluto una cosa, sino un drama: su vida" Conclusiones. O rtega ayuda a captar mejor el estrato decomprensión propio dela psiquiatría biológica porque su "nuevo nivel está en un estrato más profundo de los problemas filosóficos".

Palabras clave: Ortega and Gasset, Psiquiatría biologica, Filosofía de la psiquiatría.

\section{Referencias}

1. Kandel ER. A new intellectual framework for psychiatry. Am J Psyciatry 1998; 155: 457-69.

2. Figueroa G. Un marco de referencia nuevo para la psiquiatría: la mente encuentra al cerebro. I. Los fundamentos científicos y humanos. Rev Chil Neuro-Psiquiat 2002; 40: 307-20.

3. Kandel ER. Psychiatry, psychoanalysis and the new biology of the mind. Washington: American Psychiatric Publishing, 2005.

4. Guze SB. Biological psychiatry: is there any other kind?. Psychol M ed 1989; 19: 315-23.

5. Benjamín J Sadock, Virginia A Sadock. Kaplan \& Sadock's Comprehensive Textbook of Psychiatry. 2
Vol $7^{\text {th }}$ edition. Philadelphia: Lippincott Williams $\&$ Wilkins, 2000.

6. Santander F, coordinador. Ética y praxis psiquiátrica. Madrid: Asociación Española de N europsiquiatría, 2000.

7. Eisenberg L. Psychiatry and neuroscience at the end of the century. Forum-Psychiatry and the neurosciencies. Current Opinion in Psychiatry 1999; 12: 629-32.

8. Okasha A. Neuroscience and the future of psychiatry. Forum-Psychiatry and the neurosciencies. Current Opinion in Psychiatry 1999; 12: 633-6.

9. Kandel ER. Biology and the future of psychoanalysis: a new intellectual framework for psychiatry revisited. Am J Psychiatry 1999; 156: 505-24. 
10. Cutting J. Principles of psychopathology. Two Worlds-Two M inds-Two Hemispheres. N ew York: Oxford University Press, 1997.

11. Radden J, editor. The philosophy of psychiatry: A companion. New York: Oxford University Press, 2004.

12. Blankenburg W. Psychiatrie und Philosophie. En : Kisker KP, M eyer JE, M üller C, Strömgren E, H rsg. Psychiatrie der Gegenwart. Forschung und Praxis. Band I. Grundlagen und M ethoden der Psychiatrie. Teil 1. 2. Auflage. Springer: Berlin, 1979, págs. 82775.

13. SearleJR. The rediscovery of the mind. Cambridge: The M IT Press, 1992.

14. Changeaux J-P, Ricoeur P. Ce qui nous fait penser : La nature et la régle. Paris: Odile Jacob, 1998.

15. Changeaux J-P, editeur. Les fondements naturels del'éthique. Paris: OdileJacob, 1993.

16. Ortega y Gasset J. ¿Por qué se vuelve a la filosofía? OC IV; 1930: 89-109.

17. Heidegger $M$. Heidegger $M$. Wissenschaft und Besinnung. En: Vorträge und Aufsätze. 5. Auflage. Pfullingen: Neske, 1967. p. 41-66.

18. D'Agostini F. Analíticos y continentales. Guía de la filosofía de los últimos trinta años. M adrid: Cátedra, 2000.

19. Echeverría J. Filosofía de la ciencia. M adrid: A kal, 1995.

20. Gadamer H-G. Wahrheit und M ethode. Tübingen: Mohr; 1960.

21. Ortega y Gasset J. A puntes sobre el pensamiento, su teurgia y su demiurgia. OC V 1941; 517-47.

22. Lampedusa GTde. El gatopardo. Barcelona: Noguer, 1961.

23. Ortega y Gasset J. La idea de principio en Leibniz y la evolución de la teoría deductiva. OC VIII 1948; p. 59-356.

24. Ortega y Gasset J. ¿Quées filosofía? OC VII 1929; 273-438.

25. Ortega y Gasset J. Unas lecciones de metafísica. OC XII 1932/1933; 11-128.

26. Ortega y Gasset J. Comentario al «Banquete» de Platón. OC IX 1946; 747-84.

27. Ortega y Gasset J. La razón histórica. OC XII 1940; 147-237.

28. Ortega y Gasset J. Origen y epílogo de la filosofía.
OC IX 1953; 345-434.

29. Jaspers K: Allgemeine Psychopathologie. 8 Aufl. Berlin: Springer; 1965.

30. Kendler KS. Toward a philosophical structure for psychiatry. Am J Psychiatry 2005; 162: 433-40.

31. Kendler KS. A psychiatric dialogue on the mindbody problem. Am J Psychiatry 2001; 158: 9891000.

32. Bolton D, Hill J. Mind, meaning, and mental disorder. The nature of causal explanation in psychology and psychiatry. Oxford: Oxford University Press, 1996.

33. BickleJ. Philosophy and neuroscience: a ruthlessly reductive account. Boston: Kluwer Academic, 2003.

34. Valentine ER. Conceptual issues in psychology. London: Routledge, 1992.

35. Echeverría J. La filosofía de la ciencia a finales del siglo XX. EN : Muguerza J, Cerezo P, editores. La filosofía hoy. Barcelona: Crítica, 2000. p. 243-50.

36. Hundert EM. Philosophy, psychiatry and neuroscience. Three approaches to the mind. Oxford: Clarendon, 1989.

37. Villagrán JM, Luque, R. Bases epistemológicas de la teoría y práctica psiquiátricas. En: Luque $\mathrm{R}$, Villagrán JM. Psicopatología descriptiva: nuevas tendencias. M adrid: Trotta, 2000. p 75-106.

38. Heidegger M. Der Willezur M acht als Erkenntnis. Gesamtausgabe 47. Frankfurt: Klosterman, 1989.

39. Rosenberg R. Some themes from the philosophy of psychiatry: a short review. Acta Psychiatrica Scandinava 1991; 84: 408-12.

40. Wulff HR, Pedersen SA, Rosenberg R. Philosophy of medicine. $2^{\text {nd }}$ edition. Oxford: Blackwell, 1990.

41. Navarro JM. Facticidad y trascendentalidad En: Rodríguez R. M étodos del pensamiento ontológica. Madrid: Síntesis, 2002. p. 21-87.

42. Ortega y Gasset J. Kant. Reflexiones de centenario (1724-1924). OC IV 1924; 25-47

43. Ortega y Gasset J. Anejo a mi folleto «Kant». OC IV 1924; 48-59.

44. Bunge M. Philosophy in crisis: The need for reconstruction. New York: Prometheus Books, 2001.

45. Bunge M . Epistemología. Barcelona: Ariel, 1985.

46. Ortega y Gasset J. Ni vitalismo ni racionalismo. OC III 1924; 270-9. 
47. Ortega y Gasset J. El sentido histórico de la teoría deEinstein. OC III 1923; 231-42.

48. SlifeBD. Theoretical challenges to therapy practice and research: the constraint of naturalism. En: Lambert MJ, editor. Bergin and Garfield's $\mathrm{H}$ andbook of Psychotherapy and Behavior Change. New York: John Wiley \& Sons, 2004, p. 44-83.

49. John R. Searle. El misterio de la conciencia. BarceIona: Paidós, 2000.

50. Dennett DC. Consciousness explained. New York: Little, Brown, 1991.

51. Popper K, Eccles J. The self and its brain. New York: Springer, 1981.

52. Bunge $M$. Ten models of individualism $\%$ none of which works, and their alternatives. Philosophy of the social sciences 2000; 30: 384-406.

53. Ortega y Gasset J. Pleamar filosófica. OC III 1925; 344-9.

54. Ferry L. ¿Cómo ser materialista? Por qué abogo por un «humanismo del Hombre-Dios». En: Comte-Sponville A, Ferry L. La sabiduría de los modernos. Diez preguntas para nuestro tiempo. Barcelona: Península, 1999. p. 25-39.

55. Husserl E. DiePhilosophieals strengeW issenschaft. Frankfurt: Klostermann, 1981.

56. Popper KR. Logik der Forschung. Tübingen: Mohr, 1935.

57. Zubiri X. Naturaleza, Historia, Dios. 9ạ edición. M adrid: Alianza, 1987.

58. Ortega y Gasset J. Pasado y porvenir para el hombreactual. OC IX 1952; 645-63.

59. Ortega y Gasset J. Bronca en la física. OC V1937; 271-287.

60. Heidegger M Beiträge zur Philosophie (vom Ereignis). Gesamtausgabe 65. Frankfurt: Klostermann, 1989.
61. Heidegger M. Zur Seinffrage. Gesamtausgabe 9. Frankfurt: Klostermann, 1976. p. 385-426.

62. Heidegger M. Heidegger M DieZeit desWeltbildes. Gesamtausgabe 5. Frankfurt: Klostermann, 1984. p. 69-104.

63. Wallace E, Radden J, Sadler JZ. The philosophy of psychiatry: who needs it? J Nerv M ent Dis 1997; 2: 67-73.

64. Figueroa G. Proyecciones psiquiátricas del pensamiento de Ortega. En: Filosofía contemporánea. Jornadas Académicas de la Universidad de Valparaíso. Valparaíso: Edeval 1983; 4: 57-76.

65. Heidegger M. Ontologie (Hermeneutik der Faktizität). Gesamtausgabe 63. Frankfurt: Klostermann, 1982.

66. Heidegger $M$. Brief über den «Humanismus». Gesamtausgabe 9. Frankfurt: Klostermann, 1976. p. 313-64.

67. Figueroa G. Un marco de referencia nuevo para la psiquiatría: Ia mente encuentra al cerebro. II. Fundamentos históricos. Rev Chil Neuro-Psiquiat 2002; 40: 321-34.

68. Ortega y Gasset J. Las dos grandes metáforas (en el segundo centenario del nacimiento deKant). OC II 1924; 387-400.

69. Biemel W. Heideggers Begriff des Daseins. Studia Catholica 1949; 24: 113-29.

70. Ortega y Gasset J. Historia como sistema. OC VI 1935; 11-50.

71. Figueroa G. Goethe desde dentro: Ortega y el psicoanálisis. Revista Ciencias Sociales 1988; 32-33: 165-89.

72. Ortega y Gasset J. Pidiendo un Goethe desde dentro. OC IV 1932; 395-420.

73. Ortega y Gasset J. Sobre la leyenda de Goya. OC VII 1950; 537-63.

74. Ortega y Gasset J. Juan Vives y su mundo. OC IX 1941; 507-43.

Correspondencia:

Dr. Gustavo Figueroa Cave

Casilla 92-V

E-mail: gufigueroa@vtr.net 